


\section{Gordon Matta-Clark:}

\section{"en algún lugar fuera de la ley”*}

GORDON MATTA-CLARK: 'SOMEWHERE OUTSIDE THE LAW'

GORDON MATTA-CLARK: "EM ALGUM LUGAR FORA DA LEI"

\section{Éric Alliez**}

\section{Traducción: Sergio E. Ramos***}

Cuadernos de Música, Artes Visuales y Artes Escénicas

/ Volumen 12 - Número 2 / Julio - Diciembre de 2017

/ ISSN 1794-6670/ Bogotá, D.C., Colombia / pp. 345-361

Fecha de recepción: 28 de octubre de 2016

Fecha de aceptación: 3 de febrero de 2017

Disponible en línea: 22 de junio de 2017

doi:10.11144/Javeriana.mavae12-2.gmce

* Traducción.

* Doctor en filosofía y letras. Profesor en la Université Paris 8 y en el Centre for Research in Modern European Philosophy de la Kingston University, London.

** Sergio E. Ramos es lingüista y traductor. Algunos de sus intereses son la teoría sintáctica y el bilingüismo. Actualmente completa su tesis doctoral sobre los patrones de identidad en construcciones elípticas en la alternancia de códigos bilingüe en la Universidad de Illinois en Chicago. 


\section{Resumen}

“Nadie podía construir edificios cómo Gordon los destruía", leemos en la edición de Flash Art, publicada poco después de la muerte del artista. En este artículo, se parte de la violencia tanto física como social de las intervenciones de Gordon Matta-Clark (su "brutalidad de líneas puras"), con el fin de introducir la relación (y la negación en dicha relación) entre Matta-Clark y los arquitectos a quienes él coloca "en los extremos opuestos del polo" a su propia operación anarquitectónica. Sin embargo, lo que Matta-Clark propone no es tanto un uso alternativo del recinto del espacio, sino el diagrama de una nueva enunciación espacial que, como se intenta mostrar aquí, ofrece una perspectiva nueva de los mismos términos en los que se planteó la pregunta del arte al final de la década de 1960.

Palabras claves: Gordon Matta-Clark; Arte Contemporáneo; Arquitectura;

Anarquitectura; Diagrama; Fotomontaje; Renovación Urbana; Urbanismo

\section{Abstract}

'Nobody could construct buildings the way Gordon destructed them', we read in the issue of Flash Art published shortly after the artist's death. In this article we set out from the at once physical and social violence of Gordon Matta-Clark's interventions (their 'cleanlined brutality') so as to introduce the relation-and to introduce the negation in the relation-between Matta-Clark and the architects whom he places 'at opposite ends of the pole' from his own anarchitectural operation. But Matta-Clark proposes not so much an alternative usage of the enclosure of space as the diagram of a new spatial enunciation which, as we try to show, sheds new light on the very terms in which the question of art was posed at the end of the 1960s.
Keywords: Gordon Matta-Clark, Contemporary

Art, Architecture, Anarchitecture, Diagram,

Photomontage, Urban Renewal, Urbanism

\section{Resumo}

'Ninguém poderia construir edifícios como Gordon destruia-los', lemos na edição de Flash Art publicada pouco após a morte do artista. Neste artigo partimos da violência ao mesmo tempo física e social das intervenções do Gordon Matta-Clark (sua 'brutalidade de linhas limpas') a fim de introduzir a relação-e introduzir a negação na relação—entre Matta-Clark e os arquitetos quem ele coloca 'em lados opostos do polo' de sua própria operação anarchitectural. Mas o que Matta-Clark propõe não é tanto um uso alternativo do compartimento do espaço como o diagrama de uma nova enunciação espacial que, como procuramos mostrar, lança nova luz sobre os termos em que a questão da arte foi feita no final da década de 1960.

Palavras chave: Gordon Matta-Clark Arte Contemporânea; Arquitetura; Anarquitetura; Diagrama; Fotomontagem; Renovação Urbana;

Urbanismo 
Enfrentarse a los límites de la arquitectura misma, hacerle frente en el punto clínico (o entrópico) de su colapso material (effondrement) y presionarla hasta el punto crítico de la desconexión ideo-lógica (effondement) de su economía, tal habrá sido la función primaria de la antiobra arquitectónica, o anarquitectónica, de Gordon Matta-Clark. Una iniciativa que presupone la destrucción de la "obra": el edificio abandonado próximo a ser demolido, para una destrucción que se llevará consigo todas las intervenciones artísticas de las que habrá sido ya no el "sitio" sino el "no sitio" y la sede. La afirmación del carácter social ("tratar con las condiciones sociales directamente") ${ }^{1}$ de esta destrucción reencaminada hacia una deconstrucción (una desedificación), por medio de cortes (cortar, recortar, acortar...) infligidos al edificio en una ontología experimental del espacio urbano, sirve también como una ruptura con el Land Art o arte terrestre ("literalmente cómo dibujar sobre un lienzo en blanco") (Moure 2006, 61) y con el arte conceptual ("usando paredes en lugar del lenguaje"). ${ }^{2}$ Deshacer la pared (défaire le mur) para liberar, performativa y efímeramente, el espacio social de sus "límites arquitectónicos"3 y de su opresiva dialéctica pública/privada: es así como Gordon Matta-Clark utiliza el término no arquitectura ${ }^{4}$, para delinear la dimensión crítica de sus proyectos con respecto a la función social de la arquitectura, cuya semio-génesis capitalista (en nombre del "urbanismo," el verdadero plano de consistencia de la arquitectura) es sometida a una contra-inversión por dichos proyectos.

"Nadie podría construir edificios como Gordon los destruía" (Castle 1979). ${ }^{5}$ La violencia tanto física como social de las intervenciones de Gordon Matta-Clark, las cuales él mismo atribuyó a una "brutalidad de líneas puras"6 (y las que se tratan aquí respecto de su operación característica), implica una ruptura con la conceptualización formalista de la "arquitectura". Dicha ruptura es tan radical que la palabra extracción, con la que Matta-Clark describía sus primeros recortes, es la única manera de introducir la relación -y de introducir la negación en la relación- entre Matta-Clark y los arquitectos que para él están "en los extremos opuestos del polo"7 a sus propias intervenciones en un edificio. Es como si uno tuviera que comenzar adentrándose en el edificio, para poder luego extraerse físicamente de la estructuración arquitectónica y atacar sus cimientos funcionales. Estos cimientos son tan teóricos y sociales como materiales, dado que la "materia arquitectónica" está siempre formada de manera semiótica por su incorporación en el socius, y se encuentra más profundamente organizada que nunca cuando está sujeta a la voluntad completamente moderna de la planitud y transparencia de las "estructuras". Esta arquitectura, "proliferada por el estilo internacional [...] en el desarrollo del imperialismo norteamericano de la posguerra", explica Matta-Clark, "refleja la iconografía del eje corporativo occidental" que "ha creado una condición deshumanizada tanto en el ámbito interno como institucional". De ahí la importancia de una crítica radical de las formas actuales de la autonomía de la arquitectura; una crítica que tome incluso la forma - extrema - de una explosión de ventanas estallando los vidrios del Institute of Architecture and Urban Studies de Nueva York, fundado y dirigido por Peter Eisenmann. ${ }^{9}$ Por tanto, no es insignificante que este antiguo alumno de la Escuela de Arquitectura de la Universidad de Cornell (1962-1968) —conocida en los Estados Unidos como la escuela de Corbu-comience sus operaciones inmobiliarias concentrándose en los cimientos del espacio alternativo en 112 Greene Street (una cooperativa y residencia de artistas). ${ }^{10}$ 
Algunos meses después de su apertura por Jeffrey Lew (al final de 1970), Matta-Clark excavaría un hoyo profundo en el sótano en Greene Street y plantaría un árbol de cerezo, junto con algo de césped sobre la tierra amontonada en el piso, colgando lámparas infrarrojas por encima de toda la "instalación", que mantendrían con vida al árbol por tres meses y así determinaría la duración de la obra (Cherry Tree 1971) ${ }^{11}$. Pero lo más interesante aquí es la manera en la que el artista explica que nunca logró alcanzar su "idea real",

que fue excavar lo suficientemente profundo para poder ver los cimientos reales, los espacios "removidos" debajo de la fundación, y liberar las enormes fuerzas de compresión y confinamiento del edificio haciendo simplemente un hoyo. Poder pasar libremente por debajo de un área tan restringida gravitacionalmente, jeso habría sido increíble! ${ }^{12}$

No debería sorprender, por tanto, que después de haber expresado su deseo de "alterar todo el espacio hasta sus mismas raíces, lo que significaba un reconocimiento de todo el sistema [semiótico] del edificio", Matta-Clark concluyera que "penetrar físicamente la superficie parecía el siguiente paso lógico" (Moure $(2006,68)$. Cortar sería una cuestión de deshacer la economía inmobiliaria de la gravedad a través de la interrupción de la estriación físico-mental del espacio global operado por la administración arquitectónica de la vida y de la ciudad, hasta el punto de inducir el vértigo de un absoluto local, sus múltiples perspectivas que proliferarían por medio de perforaciones.

La penetración de la "base" de la arquitectura del espacio es así el primer momento de un proceso de prueba (la prueba de los fundamentos de la arquitectura). Este proceso se propone, asimismo, como una arqueología futura de su propia operación antiarquitectónica a través de la dialectización de la situación entrópica del edificio dentro del cual se encuentra "situado"; un edificio en el epicentro de la arquitectura entrópica del centro de Manhattan, al sur de Houston Street, al principio de la década de 1970. Hablamos de un panorama de recesión, una zona industrial abandonada poblada por los marginados y rechazados, donde los artistas "fuera del sistema" crean espacios abiertos (y cocinas abiertas) ${ }^{13}$ en el momento justo cuando la revolución económica de la globalización neoliberal — de la que el World Trade Center, aún en construcción, era el símbolo más visible- estaba ya en movimiento. ${ }^{14}$ La deconstrucción/re-construcción no estándar llevada a cabo en 112 Greene Street que también es no standart, es decir, un arte que se niega a sostenerse funcionalmente por su propia cuenta) ${ }^{15}$ se convierte en un símbolo de lo que Robert Smithson denomina "una dialéctica del cambio entrópico" (Smithson 1996, 304) y en una confirmación amenamente rígida del tema marxista de la metáfora espacial del edificio (base y superestructura), según la cual "la base es lo que en última instancia determina el edificio completo". Una confirmación que, en este caso, también implica la directriz adicional de Althusser $(1984,10)$ de pensar en lo que la metáfora nos da "en forma de una descripción," para así ofrecer "una respuesta conceptual" a "la metáfora espacial." Matta-Clark apela a una "dialéctica materialista de un entorno real" que funcione vía el hermetismo (posconceptual) de lo que está "internamente removido", con el fin de ser virtualizado en la afirmación-negación que establece. Dicha apelación se refiere, precisamente, a la excavación del sistema arquitectónico-lógico hasta el entramado de la lengua que lo apoya, cuyas metáforas más convincentes (la "columna vertebral semiótica" de sus "cimientos teóri$\left.\cos ^{\prime \prime}\right)^{16}$ se verán contrarrestadas por una suerte de "malabares sintácticos" con la "estructura 
arquitectónica en su realidad". Así es como Matta-Clark, distanciándose de todo gesto escultural (ignorando la sugerencia de Liza Bear), define la naturaleza de sus operaciones en una casa, lo cual siempre es "algo muy real, especialmente cuando se considera su entorno", especificando que se trata de una cuestión de "desintegrar cierto tipo de secuencia establecida de partes."17 Esta desintegración sintáctica es, precisamente, la proposición de una anarquitectura que opera solo a través del corte de su sintagma primario, puesto indefinidamente en variación: de una anárquico-tectura que está somewhere outside the law (en algún lugar fuera la ley), que la hace definitivamente desviarse hacía una Narco-Tecture que autoriza todas las posibles derivas, ya que (I) you are the measure (tú eres la medida), y no se puede tomar demasiado en serio como una fenomenología, puesto que (II) la postura final dice a rockingchair estate (una finca mecedora). ${ }^{18}$ Un declive que se podría extender de la siguiente manera, como en una tarjeta hecha por Tina Girouard y fotografiada para la exposición Anarchitecture, una especie de antimanifiesto en forma de una cuadrícula de palabras que permite todas las conjunciones (un/algunos crucigramas en forma de texto): "an ark kit puncture-anarchy torturean art kit torture-an art defector-etc." 19

Este "ETC." viene también de una puesta-en-variación desorganizadora (o "desintegradora") de la interminable ciudad, cuya arquitectura, dado que (como dicta la entropía) nada funciona sin que decaiga, cruzará este límite (que había sido protegido por un efecto estructural). El límite ya no significará un efecto de umbral (threshold), sino un efecto threshole que nos transportará a un mundo donde nothing works best (nada funciona mejor), dado el simple hecho de una respuesta "directa e improductiva a la forma en servicio de la función" 20. De esta manera, la productividad funcionalista de la forma arquitectónica es sometida a una antiproducción que hace un agujero en el "sistema" que moviliza el exterior que había negado (la catástrofe entrópica como exterior físico, deconstrucción de la vida urbana cotidiana como un exterior en forma de diagrama) e interrumpe la espacialización metafórica de la imagen del mundo como estructura arquitectónica. Nothing works best será, entonces, inmediatamente traducido metonímicamente a una serie desarticulada de palabras-trastorno que "verbalicen" todo el proceso de antiproducción anarquitectónica alrededor (nothing) works/words: nothing words beasts/beasts of the north words (Moure 2006, 376-737).

Por todos estos factores, lo anterior bien podría ser una des-definición perfecta del colectivo anarquitectónico que, independiente de lo que haya sido en realidad (¿un intercambio puro?, ¿una máquina teórica?), no pudo escapar de la tarea con la que se define: cómo deshacer las cosas con palabras. El colectivo de un "estado mental", al que su inspirador había aspirado con el antilenguaje de líneas puras de sus cortes, produjo in situ, pero también off-site en montajes cada vez más vertiginosos, cuya expresión transmediática debe también ser vista como una práctica real de la subversión antiformalista de la arquitectura como indicador de poder. En otras palabras: si "somos antiformales" 21 es la forma de expresión que sirve como la apertura maquinal sobre la multiplicidad de medios. Matta-Clark es el nombre propio del conjunto colectivo de enunciación anarquitectónica del cual él induce y deduce, indefinidamente: "Manteniéndolo como un proceso abierto continuo. Sin terminar/solo manteniéndolo y empezando de cero una y otra vez" ${ }^{22}$. 
Splitting (Bifurcaciones) (1974) consistió no solo en cortar verticalmente el exterior y el interior de una casa (también programada para demolición) ${ }^{23}$ por la mitad con una motosierra, sino, más radicalmente, en la fabricación de una mitad que se incline hacia atrás, para que la operación de disección fuera también un desplome de la arquitectura de vuelta a sus cimientos. Cortando una "rebanada" de $2.5 \mathrm{~cm}$, la división vertical del edificio toma el código arquitectónico de la sección al pie de la letra, rediseña la estructura intacta de la construcción en una escala de 1:1 y hace inmediatamente visible la composición de los estratos materiales que corresponden funcionalmente a las necesidades de vivienda de una familia obrera en una ciudad dormitorio de Nueva York (un gueto negro: Englewood, Nueva Jersey). Esperando a ser demolida para dar paso a una subdivisión residencial del terreno que sea más rentable, sus terrenos cubiertos de descuidada vegetación, la casa era una célula del tejido suburbano, ejemplo de su modo de producción y vivienda y de su reproducción ampliada a través de la expulsión de sus inquilinos precarios. Matta-Clark comenzó por amontonar en el sótano los restos de objetos personales y muebles abandonados por los antiguos residentes (fotografiados como testimonio de la violencia subterránea de esta "renovación urbana"). ${ }^{24}$

Como segundo paso, el cual daría su verdadera importancia a la operación (y que no estaba planeado al principio: se le ocurrió mientras llevaba a cabo la obra), Matta-Clark tornó su atención a la subestructura que el corte vertical había dejado intacta: se removió la primera capa de cimientos de bloques de hormigón en su totalidad y se socavó la mitad trasera de la casa y la dejó apoyada en gatos de tal manera que su peso total de 15 toneladas pudiera bajarse hasta que quedara inclinada en un ángulo. Este tour de force, cuyo resultado fue incierto hasta el último momento, disoció el cuadro arquitectónico de sí mismo, sinónimo de una desarticulación total del espacio, desorientadora y desfuncionalizada. La operación utilizó la misma estructura estática de la casa para arrancarla de la inercia gravitacional que aseguraba su asentamiento y después mantenerla en un estado de tensión que se extendiera a todo el interior que afectara, inquietara, la misma posibilidad de habitarla.

\footnotetext{
Comenzando desde la parte inferior de las escaleras donde la grieta era pequeña, subías, y mientras más subías, tenías que seguir cruzando la grieta. Seguía ensanchándose mientras subías por las escaleras hasta que cuando llegabas a la parte más alta, la grieta era de uno o dos pies de ancho. Realmente había que saltarla. Podías sentir el abismo en un sentido cenestésico y psicológico. ${ }^{25}$
}

De esta manera, Matta-Clark fue capaz de satisfacer su deseo, formulado en la época de Cherry Tree, de "liberar las [...] enormes fuerzas de compresión, de confinamiento" de las leyes de la gravedad y actuar sobre los cimientos con el fin de "alterar todo el espacio".

En su entrevista de 1974 con Liza Bear, narra la experiencia de bifurcarse (Splitting) de la casa:

En todo el proceso, hubo un suspenso terrible, sin saber realmente qué se sostendría y qué se desplazaría, pero la estructura actuó perfectamente [...] Se vino abajo como un sueño.

[...] todo el evento me dio una nueva percepción sobre lo que es una casa, cuán sólidamente construida, cuán fácilmente movida. 
Partiendo de su familiaridad con el mundo de la danza, en particular a través del trabajo de Trisha Brown, quien desafió las leyes de la gravedad en la ciudad con su bailarines que caminaban por las paredes. ${ }^{26}$

[...] Era como una pareja de baile perfecta [...] la realización del movimiento en una estructura estática fue emocionante. ${ }^{27}$

Uno de los efectos de la bifurcación que está particularmente bien capturado (o intensificado) por el filme en super 8 (muda, 10 min 50 s) es la sobrecogedora penetración de la luz mientras insufle el espacio de manera que lo coloca en fusión y lo libera violentamente de su principio de cierre. Dependiendo de las condiciones de luz y la posición de la cámara, lo que Ilama la atención es la nitidez de la grieta que recorre la casa, a veces oscura, a veces iluminada, y los rasgos de luz proyectados a través de la grieta, los cuales forman líneas divisorias inmateriales (no aislantes) en movimiento con el sol que reformulan constantemente el espacio interno sin fijarlo. Debido a la inclinación, la grieta se ensancha hacia la parte superior, ${ }^{28} \mathrm{como}$ si el edificio estuviera en proceso de partirse, en una puesta-en-tensión generalizada que física y ontológicamente lo desequilibra y abre al mismo tiempo. Porque lo que está en juego aquí no es la inclinación de la casa en sí (con el fin de producir una forma espectacular o cómica de la arquitectura), sino una superación, a través de la naturaleza necesariamente peligrosa e incierta de la operación, de todos los límites habituales del espacio, una superación hecha posible por el paso al límite del punto de ruptura (o uno de varios) al que se acerca lo más posible bajo la presión movilizadora de la demolición (y no solo la presión motivadora ante la urgencia de la situación). En este sentido, la inminente demolición constituye un componente vigoroso y necesario de la operación. Como tal, esta última será documentada desde la perspectiva de una historia diferente de la escrita por los vencedores "en la superficie de las cosas".

La apuesta de esta operación, tanto teórica como práctica, se basa en la oposición entre dos tipos de diagramatismo, una oposición hecha muy visible y legible por la comparación de dos fotomontajes..$^{29}$ Por un lado, tenemos el (ya icónico) ${ }^{30}$ fotomontaje que muestra la mitad del interior de (toda) la casa, seccionada verticalmente sobre un plano que coincide con el plano del material cortado (aquí invisible) que yuxtapone los diferentes cuartos, con cada uno en su respectivo lugar, pero grabado desde su propia perspectiva foto-gráfica y así subvertir tanto la representación abstracta más habitual de un espacio cúbico como la elevación técnica en corte paladiano (aquí el corte funciona como un diagrama inquietante de la celularidad general o como un diagrama que desasosiega tal celularidad). Y por otro lado, un fotomontaje como conjunto heterogéneo de una serie de vistas desplazadas/desplazantes que de-compilan el corte y la inclinación y convierten el espacio intrínsecamente flexible o maleable en el corte (en este caso, el diagrama descoordina lo que articula: por debajo y por encima, delante y detrás, hacia un lado y hacia el otro...). Los fotomontajes posteriores colocan en otras maneras las partes en variación: en algunos, la grieta parte la casa completa desde el techo hasta la planta baja, verticalmente o con un leve clinamen; otros la expanden a varias franjas, la extienden en un arco, o la hacen oscilar alrededor de su eje descentrado/de descentramiento. En todos los fotomontajes, el corte mantiene todo el espacio en un suspenso que le permite al vacío funcionar (las fotografías también capturan al mismo Matta-Clark trabajando, suspendido de un cable con las paredes). Una proliferación aguda y explotada de fotomontajes - un montaje de montajes en vez de un collage de collages - aumentada por todos los medios posibles para la expresión del espacio que vuelve infinitas sus potencialidades virtuales y su 
conjunción disyuntiva e inclusiva (una serie sin limitación de disyuntivas inclusivas que hace que el espacio difiera de sí mismo). Esta falta de limitaciones opera a través de un diagramatismo que tiene un efecto cenestésico. El espacio desterritorializado por la multiplicidad constructivista de sus expresiones — una transexpresividad maquínica — frustra tanto la labor óptica y cenestésica del collage mental (que lo reterritorializa en la imagen del cuerpo vivido; solicita este collage con el fin de deshacerlo) como la relación de alteridad (una relación no dialéctica, a pesar de las mismas declaraciones de Matta-Clark) entre las dos partes de la casa. El espectador/visitante es llevado a una partición de/en el movimiento-espacio, colocado en una situación que resulta, ya no "atmosférica", sino de aceleración cinemática y desorientación cinemato-gráfica. Más aún en cuanto que la casa fue sujeta a una tercera operación: sus cuatro esquinas superiores, donde el techo se unía con las paredes ortogonales, fueron removidas (Splitting: Four Corners) sometiendo la caja arquitectónica a una nueva separación, un descoronamiento que ahora la abre no solo a la luz sino al ambiente desolado que la rodea y, por tanto, a la vegetación salvaje en la que la cámara se sumerge, en una toma final de puro verdor, cuyo significado es incierto, excepto que deshace provisionalmente la domesticación suburbana de la naturaleza respecto de un "deshoje" (y respecto de la alianza necesaria con "sobrevivientes autóctonos") $)^{31}$. Mostradas en exposición especial en una galería (o museo), estas cuatro esquinas paradigmáticamente se refieren a aquello del cual son el vacío sintáctico, en una transferencia diagramática de la dialéctica de lugar/no lugar, de modo que "no solo sea la casa de Englewood (New Jersey) la que se 'bifurque', sino el campo representacional que ocupa", 32 más allá de cualquier tipo de formalismo reconfigurado ad litteram; aquí, sin embargo, se le hace una autopsia al formalismo.

En efecto, el icónico fotomontaje de Splitting, con su representación en corte de las relaciones estructurales entre la fachada y el interior, asocia esta autopsia con el recambio de una poderosa esquematización arquitectónica, cuyo principio se había vinculado, desde Palladio, a las anatomías de la fábrica del cuerpo humano. Esta autopsia de una disección, como comenta Caroline van Eck, característicamente produce el retorno de lo reprimido anatómico-arquitectónico por medio del cortar en el tejido/en el tejido viviente de una casa. Lo reprimido ahora puede verse como la presencia negativa de la morada de la casa en cada uno de sus "planos" autónomos, en perspectivas contorsionadas: entramos en el fotomontaje desde la planta baja (también la fotografía más grande) que muestra al fondo, en lo que fue la cocina, una estufa vieja, ligeramente fuera de lugar, a pesar de que todavía evoca la médula de domesticidad (se puede distinguir el papel tapiz y un pequeño marco). De esta manera, el proceso de abstracción constitutiva del movimiento de la arquitectura hacia un formalismo funcional se invierte en favor de la exposición de la materialidad de rastros de morada más cotidiana, multiplicada por el efecto de un fotomontaje que yuxtapone escenas de una vida ausente dentro de la que ha cortado el escalpelo del anatomista-anarquitecto. De ahí la inquietante extrañeza (Das Unheimliche) que emana de la escena del crimen (completa con danza macabra), divulgada por el que baila con casas que las da para ser percibidas (¿o perforadas?) "como un elemento muy vivo" (Moure 2006, 177).

Office Baroque (Oficina barroca) es un ejemplo perfecto de cómo la obra funciona, y se concibe, exclusivamente de manera diagramática: como una máquina de máquinas (una máquina infernal) que es multi- o transenunciativa (geométrica, material, gestual, gráfica, fotográfica, fílmica, socialmente ostensiva y discursiva); una máquina cuyo principio de existencia se basa en un aumento deliberadamente inducido, con efectos incontrolables a causa de la heterogeneidad de sus elementos y la heterogénesis que pone en marcha. Las condiciones de 
la intervención eran en principio ideales: Amberes, un importante sitio de comercio marítimo y lugar de nacimiento del "barroco" Rubens, el cuarto centenario de cuyo natalicio estaba próximo. Matta-Clark había conseguido autorización para realizar una intervención en la sede central de una operación de comercio marítima que se había ido a la quiebra ${ }^{33}$ (liquidada junto con una buena parte de las antiguas actividades marítimo-industriales de la ciudad). Esta sede estaba situada en el corazón del (muy fotogénico) centro turístico histórico (justo enfrente de Het Steen, el castillo de Amberes, junto al Museo Marítimo Nacional) y programada para demolición por la empresa que la adquirió, y que sin reservas se dedicaba a las prácticas más especulativas de renovación urbana. ${ }^{34}$ Este proyecto excepcionalmente oportuno dio fe de un reconocimiento significativo de la obra de Matta-Clark por uno de los programas en arte contemporáneo más innovadores de Europa. El programa era dirigido por Florent Bex, quien también dirigía el Internationaal Cultureel Centrum, donde se mostrarían off-site los fotomontajes Office Baroque, acompañados de un recorte en forma de un bote suspendido del techo de la galería. Un recorte in site que, se dijo, parecía más irreal y distanciado de la realidad del trabajo que las de-composiciones fotográficas "altamente manipuladas", que eran la base de la exposición, y esto, a ojos de todos, lo convirtió en un acontecimiento. ${ }^{35}$

El proyecto original de Matta-Clark, que se llamaría Sphere, consistía en cortar un cuadrante esférico de la esquina del edificio que daba a la calle, a su altura máxima (excepto en el quinto piso, situado detrás de la fachada). Este plan habría, por tanto, implicado cortar la mayor parte de la fachada que permitiría una visión al interior que habría sido aún más pública dada la naturaleza de este edificio de oficinas, de rigor implacable y anónimo. El desvalijamiento de Matta-Clark habría respetado la geometría del edificio, tanto mejor para exponer (y profanar) la intimidad de un sitio que era por naturaleza enclaustrado, con la violencia que lo habitaba disimulada en forma de figuras y contratos comerciales. Las autoridades municipales, oficialmente por razones de seguridad, pero sin duda también por temor a la apertura de esta perspectiva negativa en un lugar tan central para los planes de desarrollo turístico de la ciudad, rechazaron el proyecto y le permitieron a Matta-Clark intervenir solo en el interior del edificio. El plan para el recorte, sugerido por círculos superpuestos de una taza de té en el diseño preparatorio, consistió en los arcos de dos círculos desiguales $(45 \mathrm{~cm}$ y $30 \mathrm{~cm}$ de ancho según el plan y de un diámetro diferente para cada planta) que se cruzan, y cuya intersección (extensiones virtuales trazadas en el piso) produciría un contorno para cortes curvilíneos en forma de una balandra. Mientras los recortes avanzaban desde los grandes espacios del suelo y pisos inferiores hasta las pequeñas habitaciones contiguas en las plantas superiores, las formas dieron lugar a una serie de pequeños recortes circulares en los pisos. Estos recortes eran recogidos de las particiones verticales, cuya constricción complejizaba y desorientaba el conjunto, antes de alcanzar el nivel de la azotea donde se abrían en dos círculos que inundaban el interior del edificio con un juego de sombras y luz.

En el catálogo de Amberes, Matta-Clark explica que el diseño (jerárquico) del espacio:

determinaba cómo los elementos formales se transformaban de rebanadas circulares ininterrumpidas a fragmentos como de metralla y piezas de la forma original mientras "chocaban" con tabiques y muros. Además de la sorpresa y desorientación que esta obra estimula, crea un mapa mental especialmente gratificante. ${ }^{36}$ 
En este mapa mental, las curvas son un principio no de organización formal, sino del encadenamiento y desencadenamiento del espacio. Este principio registra la manera en que la hermenéutica más que evidente del símbolo-forma "náutico" inicial es transformado en un "hermetismo" de símbolos-fuerza que explota (de ahí el efecto de metralla) cualquier tipo de metaforización formal para volverse localmente asignificativo y genéricamente postsignifcativo del "barroco"; un barroco cuya fisiología contemporánea viene a contradecir y suprimir, in situ, la sede de esta burocracia marítima (que se había "ido a la quiebra").

Tan inteligible como el dibujo a escala puede haber parecido, ${ }^{37}$ el edificio en sí fue eliminado, incluso, de toda posibilidad de aprehensión sintética virtual. A diferencia de sus otros proyectos, este eludió lo que Matta-Clark aquí denomina una "interpretación instantánea"38 (instantánea en el sentido fotográfico); aquí con el significado de este sitio turístico "donde todo el mundo viene a tomar una fotografía" (Moure 2006, 256). Este fotogénico escenario es algo irónico en vista de la situación no solo geográfica sino temporal creada por la intervención: una situación en la que no se puede evitar perderse ("deambular de arriba abajo") (257) sin esperanza de capturar un "momento": la profundidad ramificada de los campos recortados recuerda una ruina en espera, retenida en suspenso entre una época pasada y el futuro inmediato de su demolición, una demolición ya en marcha en su disimulado presente de no sitio. De ahí la necesidad de la hipercomplejidad de los fotomontajes cibachrome de formato grande a los que Matta-Clark recurre para orientarnos a través de Office Baroque. Los planos superpuestos se encajan uno al otro de una manera que se vuelve indescriptible tan pronto como el punto de vista deja de ser rigurosamente vertical: los recortes atravesados entre sí; las vigas que los restringen y crean ángulos divergentes de visión (desde abajo/desde arriba) que acentúan el fenómeno de una indefinible toma en ángulo alto/bajo, las puertas que se agitan con el viento tomadas en un "panorama de arabescos" que solo puede ser documentado con un collage de 45 grados de dos fotografías; los acoplamientos sesgados de los negativos logran colapsar el espacio y hacen que cada dirección fluctúe violentamente (hasta el punto de hacer bailar la fachada desensamblada/ reensamblada [démonté/remonté] en una secuencia de fotografías tomadas del exterior con vistas al interior); las perforaciones escalonadas de los bordes de las fotografías adyacentes hacen que los planos se deslicen y rocen uno contra el otro (como en un tiempo cinemático abstracto de duraciones agregadas), mientras que los colores de Cibachrome artificialmente ajustados completan la desrealización de la escena al sobreexponer (junto con la coreografía de cortes ya no fotografiados sino fotográficamente ampliados e intensificados o "aumentados" en los montajes) su inquietante extrañeza. Tan lejos como puede estar de cualquier fenomenología (del cuerpo vivido), esto es un cuerpo totalmente desterritorializado por una desorientación espacio-temporal amplificada por la ordalía transmediática con que se enfrenta el espectador (y la cual no puede ignorar off-site ), un proceso de prueba que anima este espacio y lo sumerge, con su energética abstracto-concreta, en un mise en abyme.

Mas la negativa de Matta-Clark a la instantánea, una negativa a la cual toda su práctica lo había llevado, y que cada vez más lo llevaba a no usar tomas estáticas a menos que fueran desensambladas (dé-monté) y sus colores artificiales, con las perforaciones de la tira de película visibles (lo que guarda relación con la de-mostración o de-definición de estas fotografías con respecto a su función indicial y documental), esta negativa también marca la mayor distancia de la "retórica de indiferencia" del fotoconceptualismo, cuyo formato Matta-Clark había adoptado solo para desviarlo de su uso adecuado: la imagen ya no se deshace desde fuera mediante la neutralización de sus efectos no documentales, sino que se deshace al precipitar al 
espectador en la bifurcación multiplicada de un "interior" hecho habitable por una proyección en forma de un montaje hiperconstructivista de cortes deconstructivos de edificios, cortes convertidos en cuasicuerpos que canibalizan al espectador y lo desterritorializan "alrededor y en su totalidad" (en palabras de Briony Fer). Porque este round habrá sido tan visiblemente manipulado que es extrañamente inquietante, incluso destructivo para esa presencia de haber estado presente con la que se asocia en general a la fotografía: ya no es el signo- forma de una irrealidad real que da acceso al estar presente "natural" de los objetos en el espacio (aunque sean solo como ruinas), sino el signo-fuerza de una realidad de lo irreal, cuya génesis ha sido deconstruida por todo el mecanismo de desconstrucción al implicar la planificación territorial del presente como "ruinas en espera" en dicho génesis.

¿Y acaso este "en espera" no entra en juego en la pérdida de referencia ("indicial") en fotografías ("desechables") 39 , cuyo montaje actúa como una demostración crítica de su no sitio original en el que vivimos, simplemente, en la poshistoria que es la nuestra (poshistoria como historia del no sitio), frente a estos fotomontajes capaces de fusionarse con nosotros que nos reaniman con su cuasicuerpo? De ahí la necesidad de la subversión metafísica de la óptica fotográfica, en fotomontajes que contradicen la supuesta transparencia del medio para re-presentar un espacio dado solo para que nosotros podamos perdernos en el "círculo" de sus deconstrucciones y de la demolición prevista que prohíbe todo "acceso" a él. ("Tienen que atravesarlo", Matta-Clark repite incansablemente, pero no podemos [entrar], y él lo sabe.) Excluyendo toda "obra escénica instantánea", desafiando "todo ese carácter de objeto [que] tiene toda escultura" (incluso escultura "extendida"), ${ }^{40}$ es la participación en esta inaccesibilidad que se encuentra, en última instancia, en fotomontaje y ofrecida a nosotros como un desmantelamiento (démontage) de lo que Matta-Clark Ilama "una especie de pieza interna" (Moure 2006, 319).

Lo radical de la desterritorialización espacio-temporal del sitio qua no sitio producida por los cibachromes de Office Baroque puede evaluarse comparándolos con los de Conical Intersect, una intervención hecha en París algunos años atrás (en 1975), que consistía en labrar, a través de tabiques y vigas, un gran volumen cónico entre la pared externa del tercer y cuarto piso de una casa, hasta el techo inclinado del ático de la casa vecina.

El propósito de Conical Intersect era otro. En cuanto a la interacción con el "tejido urbano", esta es la intervención de Matta-Clark más pensada. Aquí el principio del recorte circular ya no se limita a un solo lugar/no lugar, sino que es un recorte propiamente transhabitacional que atraviesa dos edificios adosados de finales del siglo XVI, condenados por razones de saneamiento y deterioro, en el contexto de la Renovación Gaullista de la planicie Beaubourg y Les Halles..$^{41}$ Matta-Clark cortó un cono truncado en los edificios en el plazo de dos semanas con ayuda de dos asistentes. El corte tenía cuatro metros de ancho que comenzaba en la pared que daba a la calle, dos metros de ancho en el techo de la otra casa, y su eje estaba inclinado a unos $45^{\circ}$ hacia la calle Beaubourg, una arteria de circulación norte-sur importante. Este avance merece de hecho ser llamado un cruce (intersection), ya que, en el lado norte, cogía el edificio y la carretera transversalmente y los abría ampliamente uno hacia el otro, mientras que en el lado sur tenía en su mira el Centro Georges Pompidou, cuya armadura esquelética, en el fondo, empujaba hacia el cielo su red metálica de mástiles, vigas de refuerzo y lazos verticales y sus plataformas apiladas — un avatar tecnológico moderno del damero- como una araña que extendía inexorablemente su gigantesca red. El cono entrecortado en los dos edificios antiguos bien podría haber sugerido un proyectil dirigido al Centro Pompidou (y después de todo, ¿no se hablaba del Beaubourg como de un "edificio con todas sus tripas colgando"?). 
Principalmente puesto que esta proyección mental con una inclinación de $45^{\circ}$ no era tan diferente en forma y escala del manto tubular transparente que cubría las escaleras externas del edificio; una de las características más famosas del proyecto arquitectónico de Piano y Rogers. Si Matta-Clark presentó su intervención como una especie de "espectáculo de luz y sonido sin luz ni sonido" 42 (¿debemos de entenderlo como un anti-Beaubourg?), lo hizo como publicista irónico de su proyecto para el público francés; no solo una audiencia de arte de espectadores, sino un público de la calle, con el que deseaba ventilar el significado de una intervención que podría ser (y sería) acusada de "colusión con las fuerzas de destrucción y la renovación"43 de la que el Centro Beaubourg parecía ser el cabezal. Y, sin embargo, es este agujero negro, esta "máquina de vacío" 44 que cada una de las fotografías documentales de Conical Intersect muestra (montre) y desmonta (démonte), su principal característica es que siempre presenta (en blanco y negro) la intersección de interior y exterior.

En su manuscrito de borrador para la propuesta del proyecto, Matta-Clark explica que los dos edificios, construidos en 1700 por "el Señor+Sra. De Lesseville" (una pareja de edificios), no tienen ninguna gran importancia histórica fuera del hecho de que se encuentran entre los últimos a ser demolidos bajo la rúbrica de la "modernización gaullista y de Pompidou de Les Halles y la planicie Beaubourg"; "se encuentran en pleno relieve por tener en el fondo la inmensa estructura en forma de puente del Centro Pompidou que se abrirá pronto." ${ }^{45}$ Matta-Clark diría después que Conical Intersect constituyó una "contrapartida no monumental" al Pompidou, ${ }^{46}$ mas inmediatamente se puede ver el problema aquí, y la imposibilidad de resolverlo a través de una "solución" u otra: con su armadura de tubería que declara que nuestro único modo temporal es el del ciclo acelerado y de reciclaje, el Centro no es realmente un centro, sino que se extiende como una "nueva telaraña de cultura" 47 que, a su vez, como Baudrillard apunta correctamente, ya "argumenta en contra de la mentalidad tradicional o monumentalidad" $(1982,3)$.

Invitado bajo los auspicios de la 9 Bienal de París, Gordon Matta-Clark había propuesto inicialmente que su participación consistiera en hacer cortes en las plataformas y los techos del Centro, con el fin de (como propuso, con cara seria) permitir el juego de luces en el edificio (Jenkins 2001, 5). No obstante, como él sabía bastante de la controversia sobre el Beaubourg para que el recinto pudiera desempeñar un papel en cualquier intervención suya en París, el proyecto propuesto pudo formularse en términos más radicales, dado que todo el contenido artístico del Beaubourg se vuelve anacrónico por esta posestructura arquitectónica a la que "solo un vacío interior podría haber correspondido" (Baudrillard 1982, 4). Este vacío será cortado anarquitectónicamente para llevar a cabo lo que el cadáver arquitectónico del Beaubourg declara pero que "el Museo Beaubourg quiere ocultar," como afirma Baudrillard (5).

En una ruptura con todo lo que Matta-Clark había producido hasta este punto, el recorte claro en la estructura del edificio, apenas construido, revestido en su esqueleto metálico protector, habría perdido todo carácter estratigráfico y habría hecho un hueco en lo que sustituye toda inscripción de duración dentro de los espacios de la vida: a saber, una temporalidad de "justo a tiempo", cuyas conexiones superficiales se articulan con "la ideología de la visibilidad, transparencia, polivalencia, consenso, contacto" (4), que alinea la gestión de las relaciones sociales con los principios de una regeneración cultural que preside sobre la renovación urbana de la metrópoli. Se debe destacar aquí la fuerte convergencia entre la verdad neogaullista de la época Pompidou, de la que el Beaubourg era el escaparate "internacional" (en respuesta a un mayo del 68 que fue no menos), que Matta-Clark llama la "orgía de modernidad gaullistaPompidou", ${ }^{48}$ y un nuevo contexto artístico, cuya tendencia se había previsto en Nueva York por 
la transformación progresiva de la comunidad creativa de un gueto de artistas en un proyecto piloto para la nueva economía global (no solo del mercado del arte); en otras palabras, SoHo. Matta-Clark no habría tenido ninguna dificultad en reconocer las condiciones de la aceleración del proceso en los circuitos culturales integrados de la metrópoli posindustrial propuesto en Beaubourg como el modelo para todas las futuras formas de "socialización" controlada; un programa que Baudrillard resume, en una frase con un tono por más situacionista, como la "retotalización de todas las funciones dispersas del cuerpo y de la vida social (trabajo, ocio, medios de comunicación, cultura) dentro de un espacio-tiempo único y homogéneo"49

Con esto en mente, es absolutamente comprensible que la Bienal de París debió haberse negado (o repetir la negativa del Beaubourg) a un proyecto que — para seguir minando la vena situacionista con la que Matta-Clark se identificaba- habría, en efecto, hecho visible esta negación de la vida a través del desvío del vacío de un "centro", que su operación, en una inversión del procedimiento habitual, lo habría reprocesado en una ruina del presente, incluso antes de completar su construcción. Si la intervención real mantuvo al Beaubourg en su mira, entonces solo pudo hacerlo funcionando como una especie de flecha que apunta más allá de las fachadas en ruinas de los últimos edificios en pie en el vacío ambiental, que se convierten en el sitio anacrónico de un "nuevo estándar [no menos ] extravagante de sol y aire para inquilinos." ${ }^{50}$ De esta manera, el consumo visual característico de la institución del museo que se conserva detrás de la red tubular del hipermercado cultural pudo invertirse, de una manera más que duchampiana, en un "Étant d'art pour locataire" (como arte para el inquilino). Un locataire que Matta-Clark deletrea locatair, en relación otra vez con Duchamp, respirateur del aire de París, en los títulos de su película, que también se permiten una intersección cónica, ahora disminuidos a un subtítulo.

Sobreponiendo la abreviatura "libresca" de sección (=secc.) en el corte anarquitectónico y su (supuesta) construcción inter-subjetiva de situaciones en la ausencia de cualquiera de los locataires restantes (a los que se les da un regalo de un hueco de vida y luz que no podía ser más que un Étant-d'art opuesto a su museificación contradictoria), el efecto de secciónsecta fue garantizado a través de la metaironía en el campo de la seña (Du-champ du signe), movilizada de tal modo en contra del "universo total de señas" del nuevo centro (Baudrillard 1982, 3). El efecto Duchamp se confirma por la declinación (o colocación en variación) de otros nombres para la intervención, nombres cuyo sintagma primario se da con Quel con, en referencia explícita al $\angle H O O Q$ de Duchamp. ${ }^{51}$ De esta manera, el juego mediático-comercial sobre una mona lisa reducida a la reproducción más común se remitía a las "contradicciones" del Museo Beaubourg, mientras que el restablecimiento del género (femenino/masculino, con/ cône) funciona a través de la pareja de edificios (quel cône!) a punto de ser "afeitado" a favor de ella. Por consiguiente, es este indiscutiblemente un homenaje a un artista —un gran amigo y cómplice de su padre, el pintor Matta-, que fue además padrino de Matta-Clark, y a quien rindió vibrante homenaje a su muerte en 1968 ciñendo las estelas funerarias de un cementerio con una milla de cuerda y así revivir una obra de Duchamp que se convertiría en objeto de una retrospectiva (dirigida por Jean Clair), con ocasión de la apertura del Centro Pompidou, en 1977. Pero no menos evidente es la diferencia anarquitectónica de Matta-Clark en relación con el anartista que no ocultó su apoliticismo soberano, y que, en 1968, consideró oportuno recordarnos que "el arte no es como un movimiento político". Impulsado por la intersección en el (no) lugar del reprocesamiento hipercontemporal del arte y la cultura, el problema se vuelve el de la diferencia que se puede oponer a él, cuando la resistencia a la ideología de la 
producción cultural ya no sabe cómo tomar cualquier ruta que no sea reaccionaria y establecer una defensa del arte y del artista con acentos indiscutiblemente duchampianos. Así como un Baudrillard afligido por la "simulación" escribe denunciando la ficción humanista de la cultura alrededor de la cual los opositores del Beaubourg se habían reunido: "La cultura es un recinto de clandestinidad, seducción, iniciación e intercambio simbólico, altamente ritualizado y restringido. No se puede evitar Peor para el populismo. Duro para Beaubourg" (Baudrillard, 1982, 3).

Algo que en el campo puede sugerir la necesidad de un "padrinocidio", si no hubiera ocurrido ya de manos de esa focalización anarquitectónica, como un nuevo étant donné, de un arte por lo demás contemporáneo, que se opone al Disneylandia del sueño estético (ya sea aristocráticamente distanciado o democráticamente compartido), un laboratorio colectivo de ficciones prácticas.

\section{NOTAS}

1 Ver la entrevista con Donald Wall, "Gordon Matta-Clark's Building Dissections", Arts Magazine, mayo de 1976, reproducido en Moure $(2006,61)$

2 Matta-Clark, "Completion Through Removal", entrada de catálogo sin fecha, en Moure (2006, 89).

3 Matta-Clark, "The Earliest Cutout Works', sin fecha, en Moure $(2006,136)$.

4 Entrevista en diciembre de 1974 con Liza Bear en Avalanche (Matta-Clark y Bear 1974), reimpreso en Moure $(2006,166)$.

5 Tenemos, por tanto, una verdadera artimaña de la historia en acción, en el hecho de que el archivo de MattaClark se encuentra hoy en un centro de arquitectura. Que se pueda retroactivamente juzgar esto como necesario no contradice la proposición.

6 Matta-Clark y Bear (1974), en Moure (2006, 172).

7 Según la versión completa de la entrevista con Donald Wall (de la que se ha publicado solo una versión resumida, ver arriba) depositada en el CCA (Montreal), en Ursprung $(2012,30)$.

8 Entrevista con Wall, en Moure $(2006,65)$.

9 Invitado en 1976 a la exposición Idea as Model (jtodo un programa!), organizada por el Institute of Architecture and Urban Studies de Nueva York, Matta-Clark colocaría fotos de edificios del sur del Bronx con ventanas rotas entre las ventanas del Institute, antes de romper desde afuera todas las ventanas con el uso de un rifle de aire... Su participación sería suspendida inmediatamente por Peter Eisenman, quien llegó incluso a hablar de una Kristallnacht, y todas las ventanas repuestas al siguiente día.

10 Y la primera de su tipo en lo que aún no se conocía como SoHo, sino todavía como Downtown.

11 Ver fotografía en Diserens et al. $(1993,78)$.

12 Entrevista con Wall, en Moure $(2006,68)$.

13 En 1971, Matta-Clark, junto con Carol Goodden y otros amigos artistas (Suzy Harris, Tina Girouard, Rachel Lew), abrieron un restaurante/espacio alternativo llamado Food situado en (lo que se convertiría en) el barrio de SoHo.

14 Los artistas son a la vez sus disidentes más agresivos y sus agentes involuntarios, con el anuncio y diseño del aburguesamiento que se llevaría a cabo en SoHo a partir de 1973. 
15 Haciendo eco a una cita de Le Corbusier usada hasta hoy en día: “Establecer un 'standart' es agotar todas las posibilidades prácticas y razonables, deducir un tipo reconocido que sea consistente con la función, el rendimiento máximo con un costo mínimo de recursos, la mano de obra y los materiales, las palabras, las formas, los colores, los sonidos" (Le Corbusier 1973, 108, en Le Corbusier 2008, 186).12

Entrevista con Wall, en Moure $(2006,68)$.

16 Cf. Marianne Brouwer, “Laying Bare", en Diserens (1993, 51-52).

17 Matta-Clark, entrevista con Liza Bear (1974), "Gordon Matta-Clark: Splitting the Humphrey Street Building", Avalanche, diciembre de 1974, reimpreso en Moure $(2006,172)$.

18 Cf. Matta-Clark, "Proposal of Anarchitecture" (1974), Cuaderno, reproducido en Sussman (2007, 97), placa 41.

19 Reproducido en Mark Wigley, "Anarchitectures", en Von Ameluxen, Lammert y Ursprung (2012).

20 Gordon Matta-Clark, Cuaderno, en Moure (2006, 376-737) [cursivas nuestras].

21 Gordon Matta-Clark, "Our European Heritage", Cuaderno, sin fecha, Moure (2006, 365). La nota lee: "La anarquitectura se refiere a los modos de funcionamiento; somos antiformales".

22 Gordon Matta-Clark, tarjeta artística titulada "Anarchitecture", reproducida en Moure (2006), páginas finales (sin paginar).

23 La casa y sus alrededores habían sido comprados, no sin un fin especulativo, por Holly Solomon, la esposa del galerista que era un amigo muy cercano a Matta-Clark. Pero el proyecto de renovación urbana nunca se terminó. Los Solomon organizarían una excursión en autobús para visitar Splitting después de las "obras" en junio de 1974.

24 Dos fotografías de estos "restos" se presentarían en el libro de artista de pequeño formato (17 fotos en blanco y negro, sin texto) hecho por Matta-Clark (reproducido en Diserens 1993, 170-174).

25 Entrevista con Joan Simon, en Jacob $(1985,33)$.

26 Cf. Trisha Brown Company, Hombre caminando por el lado de un edificio, 1970; Caminando en la pared, 1971. La socia de Matta-Clark, Carol Goodden, bailó en la compañía de Trisha Brown. Splitting también marcaría el final de su relación.

27 Matta-Clark, entrevista con Liza Bear, en Moure $(2006,175)$. Ver también esta declaración en la entrevista con Donald Wall: "Los edificios son entidades fijas en las mentes de la mayoría; la noción de espacio mutable es prácticamente tabú" (66)

28 Véase testimonio de Joan Simons.

29 Moure (2006), fotos en 153 y 155.

30 Que aparecen, por ejemplo, en la portada del volumen Gordon Matta-Clark de Phaidon.

31 Cf. Matta-Clark, Cuaderno ca. 1969-1971, en Moure (2006, 75). En estos textos fragmentarios titulados "Cannibalism Suburbia", Matta-Clark contrapone la necesidad de un canibalismo "renovado" al "canibalismo" de jardines suburbanos ("fincas industriales"), desarrollados industrialmente contra todas las "fuerzas espontáneas de la vida" (comenzando con los bosques): "Ahora es el momento para un canibalismo renovado...", en el cual la anarquitectura participe en forma de un eat-a-tecture. Esto, a su vez, nos remite nuevamente a las primeras "rebanadas" de pared que cortó Matta-Clark en el contexto del funcionamiento del restaurante-cooperativa Food: momento en el cual él hizo, muy performativamente, jun sándwich de pared!

32 Briony Fer, “Celluloid Circus: Gordon Matta-Clark's Color Cibachromes," en Sussmann (2007, 139).

33 En inglés, la frase (broke) suena sorprendentemente similar a barroco (baroque) cuando lo pronuncia un estadounidense.

34 En un texto manuscrito que lleva por título "Office Baroque", Matta-Clark menciona la futura construcción de un Hilton Antwerp (Moure 2006, 228).

35 Thomas Crow, “Gordon Matta-Clark', en Diserens (1993, 113).

36 Catálogo de Amberes (1977), en Moure $(2006,257)$ [cursiva nuestra].

37 Reproducido en Diserens $(1993,291)$. 
38 Catálogo de Amberes (1977), Moure (2006, 257): "eludiendo lo que yo llamo interpretación instantánea".

39 Expresión de Matta-Clark, en su entrevista con Judith Russi Kirshner (febrero de 1978), en Moure (2006, 319). Al principio de la entrevista, Matta-Clark recuerda que "nadie en América fuera de Nueva York alguna vez ha visto —-muy pocas personas han visto— cualquiera de [sus] proyectos" (317).

40 Moure (2006, 319-321): “Incluso con las personas que han escapado del llamado 'hábito de la escultura' yendo a una especie de paisaje o situación territorial más allá de una galería o museo".

41 Texto introductorio para la película Conical Intersect por Gordon Matta-Clark y Bruno de Witt (1975, 18, 40 m, color, silencio, $16 \mathrm{~mm}$ ).

42 "Excepto por el sonido del tráfico abajo", añade Matta-Clark en su entrevista con Elisabeth Lebovici, citada en Joan Simon, "Motions Picture: Gordon Matta-Clark", en Sussman (2007, 132-133). O "un silencioso 'son et lumière"," como se lee en los títulos de la película.

43 Matta-Clark, entrevista con Judith Russi Kirshner, en Moure (2006, 330).

44 Baudrillard $(1982,3):$ "Todo el barrio alrededor es simplemente una zona de amortiguación, de-cubierta, desinfectada, por el diseño pedante e higiénico".

45 Gordon Matta-Clark, “Étant d'art pour locataire," Moure (2006, 182).

46 Entrevista a Matta-Clark en Amberes, en Moure $(2006,256)$

47 Gordon Matta-Clark, Étant d'art pour locataire, en Moure (2006, 182).

48 Gordon Matta-Clark, "Étant d'art pour locataire", en Moure (2006, 182)

49 Ibíd., 319

50 Entrevista en Amberes, Moure (2006, 256).

51 Cf. Entrevista con Gerry Hovagimyan, en Jacobs $(1985,88)$. 


\section{REFERENCIAS}

Althusser, Louis. 1984. Ideology and Ideological State Apparatuses (Notes toward and Investigation). En Essays on Ideology, 1-60. Londres: Verso.

Baudrillard, Jean, Rosalind Krauss y Annette Michelson. 1982. The Beaubourg-effect: Implosion and Deterrence. October 20:3-13.

Castle, Ted. 1979. Gordon Matta-Clark. Flash Art 40, n. ${ }^{\circ} 252:$ 86-89.

Diserens, Corinne, Judith Russi Kirshner, Dan Graham, Mariane Brouwer, Eugenio Trias y Richard Nonas. 1993. Gordon Matta-Clark. Marsella: Musées de Marseille.

Jacob, Mary Jane, Robert Pincus-Witten y Carrie Przybilla. 1985. Gordon Matta-Clark: A Retrospective. Chicago, IL: Museum of Contemporary Art.

Jenkins, Bruce. , 2011. Gordon Matta-Clark: Conical Intersect. Afterall Books.

Le Corbusier. 2008. Towards an Architecture. Traducido por John Goodman. Londres: Frances Lincoln.

Moure, Gloria, ed. 2006. Gordon Matta-Clark: Works and Collected Writings. Barcelona: Poligrafa.

Smithson, Robert. 1996. Entropy Made Visible: Interview with Alison Sky. En The CollectedWritings, editado por Jack Flam. Berkeley: University of California Press.

Sussman, Elisabeth, ed. 2007. Gordon Matta-Clark: You Are the Measure, catálogo de exhibición. Nueva York, New Haven y Londres: Whitney Museum of American Art, Yale University Press, 97, placa 41.

Ursprung, Philippe. 2012. Gordon Matta-Clark and the Limits of Architecture. En Gordon MattaClark: Moment to Moment: Space, editado por Hubertus von Ameluxen, Angela Lammert y Philippe Ursprung, eds. Núremberg Verlag für Moderne Kunst.

\section{Cómo citar este artículo:}

Alliez, Éric. 2017. "Gordon Matta-Clark: "en algún lugar fuera de la ley". Cuadernos de Música, Artes Visuales y Artes Escénicas 12 (2): 345-361. [https://doi:10.11144/Javeriana.mavae12-2.gmce] https://doi:10.11144/Javeriana.mavae12-2.gmce 